\title{
Psychosocial Stress in High Risk Pregnancy

\section{Abstract}

Objective: A high risk pregnancy may introduce additional psychological stress on a pregnant woman. The aim of this study was to review systematically the available evidence of the psychological consequences, in terms of anxiety and depression, of high-risk pregnancy.

Methods: A systematic search of the electronic databases was performed. This review considered only quantitative, primary studies in the English language, published during the period 2000-2015 and relevant to the objective. The population of interest was previously high-risk pregnant women. Outcome variables were general anxiety, depressive symptoms and pregnancy-specific anxiety. Seven studies met the inclusion and methodological criteria and were included in the review.

Results: The review revealed that high-risk pregnant women had high levels of depression ranging from $18 \%$ to $58 \%$ and these rates decrease throughout the course of hospitalization and are similar between women hospitalized in a hospital/health centre and women bed-rested in home. The review identifies additionally the main psychosocial variables that were related to antenatal anxiety and depression in high-risk pregnancy.

Discussion: Future studies should overcome specific limitations. Health care professionals should enhance the implementation of psychological screening and counselling to populations of high-risk pregnant women hospitalized in a hospital/health centre or bed-rested in home.
Kleanthi Gourounti ${ }^{1}$, Natassa Karpathiotaki ${ }^{1}$, Grigoris Vaslamatzis ${ }^{2}$

1 Department of Midwifery, TEl of Athens.

2 Medical School, University of Athens, Eginiteion Hospital.

Contact information:

Claire Gourounti.

"' clairegourounti@yahoo.gr

\section{Keywords}

High risk pregnancy, hospitalization in pregnancy, anxiety, depression, antenatal stress. 


\section{Introduction}

Pregnancy may involve major biological and psychological and social changes that have been linked to an increase in anxiety and depression symptoms [1]. The current literature suggests that the rate of antenatal depression ranges from $4.8 \%$ up to $40 \%$ [2, $3,4]$. Moreover, the incidence rate of anxiety during pregnancy has been reported to range between 6.8 and $59.5 \%$. [4, 5, 6, 7, 8, 9] Although the prevalence and the risk factors of anxiety and depression in pregnancy have been extensively investigated, it is noteworthy, that investigation of the prevalence and the predictive factors of anxiety and depression in high risk pregnancy is a relatively neglected area of research [10].

A pregnancy may be defined "high risk" on the basis of an increased probability of fetal anomaly, compromises to maternal or fetal health, or significant risk for maternal or fetal demise [11]. The identification of a high risk pregnancy may introduce additional stress, anxiety, depressive symptoms and uncertainty on a pregnant woman. Women with high risk pregnancies seem to have high rates of bed rest. Bed rest includes movement restriction, confinement and isolation, and together these three factors may have severe serious adverse physiological and psychological effects. Furthermore, bed rest is often an integral component of hospitalization. Prenatal hospitalization is associated with numerous stressors, such as separation from family and home and boredom. Specific stressors such as lack of activity, bed rest, hospitalization, tests and treatments and feelings of uncertainty and lack of control will be experienced by high-risk pregnant women.

Anxiety, depression and other stressful feelings during prenatal period can easily lead to more severe diseases which may be harmful to the mother, fetus and the expectant newborn's health [9]. Therefore, a better understanding of prevalence of psychological stress in high-risk pregnancies is imperative. The aim of this study was to review systematically the available evidence of the psychological consequences, in terms of anxiety and depression, of high-risk pregnancy

\section{Methods}

\section{Search Strategy}

A systematic search of the psychological and medical electronic databases (Medline, PsycINFO, CINA$H L, E M B A S E$ and Scopus) was undertaken at the beginning of 2015 to identify studies that related psychological distress (assessed by questionnaires and instruments) to high-risk pregnancy. The following search terms were used: high-risk pregnancy, abnormal pregnancy, antenatal medical disorder, obstetric risk, obstetric inpatiens, hospitalization, bed rest, stress, distress, anxiety, depression, mood disorders. Other methods of searching were used, such as searching the reference list of retrieved articles to identify additional studies that might not have been picked up by the electronic search, manual searching of relevant journals and searching for relevant textbooks.

\section{Selection criteria}

Only primary, quantitative studies in the English language were included in this review; reviews and qualitative studies were excluded. Studies included were published during the period 2000-2015. Dependent variables have been represented by various constructs, including anxiety, depression, and negative mood states. The population of interest was high-risk pregnant women that were either hospitalized in hospital or bed resting in home. Studies involving high-risk pregnancy after an assisted reproductive technology therapy were excluded. In addition, studies that included high-risk pregnant women with a lower age of 18 years old were also excluded.

Studies that met the inclusion criteria were then evaluated for methodological quality, using the 
STROBE criteria [12]. The STROBE criteria are a checklist of items that should be addressed in reporting cohort, case-control, and cross-sectional studies. In this review, we have adapted the criteria from the STROBE checklist that could be applied to the eligible studies. Criteria for evaluating methodological quality of included studies were: 1) evidence of response rate higher than $70 \%, 2$ ) evidence that each psychological outcome (distress, anxiety, depression, mood state) was measured by using standardized, validated instruments, 3) control of confounding variables and 4) information about sample size calculation. Studies that provided evidence of measuring each psychological or social outcome by using standardized, validated instruments ( $2^{\text {nd }}$ criterion) and met at least one out of the remaining two methodological quality criteria were finally included. Quality assessment and data extraction was conducted by two reviewers, using these explicit criteria.

\section{Search Results}

The initial search generated 41 titles. Titles and abstracts were examined for relevance to the review objective. After the assessment of the titles and abstracts, 34 references were excluded because they were not relevant to the objective of the study. These references were specifically excluded for the following reasons: reviews, used qualitative methods, were studies that participants were asked to recall retrospectively their feelings, measured biological stress. Therefore, the data of the 8 studies that met the inclusion criteria were analyzed by reading the full text and were evaluated for methodologic quality. These studies finally accepted for the review (Table 1). Only data relevant to this review were included from studies which also investigated other matters such as psychosocial predictors of antepartum anxiety and depression.

\section{Results}

\section{Methodological characteristics of included studies}

\section{Study location}

Three of the 7 studies took place in United States of America $[13,14,15]$; three studies were conducted in Europe $[10,16,17]$ and one study conducted in Asia [18].

\section{Study design}

Two of the 7 studies were prospective cohort studies $[13,15]$, and six were cross-sectional studies $[10,14,16,17,18]$. Both of the prospective studies had assessment points both antenatally and postnatally $[13,15]$. The majority of studies included high-risk pregnant women who were hospitalized in a hospital or a health centre. Only one study [16] included participants that were either hospitalized in a hospital or bed-rested in home. The majority of studies used specific inclusion criteria for controlling certain confounding psychosocial (e.g., no previous history of psychological illness) variables. In addition some $[13,16]$ studies also incorporated statistical analyses, such as regression analyses, for controlling confounding variables.

\section{Samples}

All of the studies included a group of high-risk pregnant women but none of the studies included a control group of low-risk pregnant women. The size of the samples ranged from 20 women to 367 couples, and the size of the control samples ranged from 55 to 200. The vast majority of studies included $<100$ women $[13,15,16,17]$, while three studies included more than 100 high-risk pregnant women $[10,14,18]$. Only one study in this review [15] provided a power calculation. The majority of the studies included high-risk pregnant women with threatened preterm labour, preterm-premature rupture of membranes, preeclampsia, hypertension, 
Table 1. Methodological characteristics of included studies.

\begin{tabular}{|c|c|c|c|c|c|c|c|c|}
\hline $\begin{array}{l}\text { Author, } \\
\text { year }\end{array}$ & Country & $\begin{array}{l}\text { Study design/ } \\
\text { gestational age }\end{array}$ & $\begin{array}{l}\text { Sample } \\
\text { size }\end{array}$ & $\begin{array}{l}\text { Sample } \\
\text { size } \\
\text { calculation }\end{array}$ & $\begin{array}{l}\text { Response } \\
\quad \text { rate } \\
>70 \%\end{array}$ & $\begin{array}{l}\text { Inclusion } \\
\text { criteria }\end{array}$ & Standardized methods & Main Results \\
\hline $\begin{array}{l}\text { Gourounti } \\
\text { et al., } 2015\end{array}$ & Greece & $\begin{array}{l}\text { Cross sectiona I/9- } \\
37 \text { weeks }\end{array}$ & $\begin{array}{l}133 \\
\text { hospitalized } \\
\text { in hospital }\end{array}$ & No & Yes (89\%) & $\begin{array}{l}\text { No previous } \\
\text { history } \\
\text { of mental } \\
\text { disorder, high } \\
\text { fluency of } \\
\text { language }\end{array}$ & $\begin{array}{l}\text { State-Trait Anxiety } \\
\text { Inventory, } \\
\text { Edinburgh Postnatal } \\
\text { Depression Scale (EPDS). }\end{array}$ & $\begin{array}{l}\text { - Means for STAI-state, STAI -trait and EPDS } \\
\text { scores were } 49.3,45.1 \text { and } 12.5 \text { respectively. } \\
\text { - } 53.4 \% \text { had EPDS scores > } 11 . \\
\text { - } 9 \% \text { scored positive on the EPDS suicide } \\
\text { screening question (question \#10). }\end{array}$ \\
\hline $\begin{array}{l}\text { Byatt et al., } \\
2014\end{array}$ & USA & $\begin{array}{l}\text { Prospective } \\
\text { longitudinal- Initial } \\
\text { survey and follow } \\
\text { up on weekly basis } \\
\text { for women who } \\
\text { remained in the } \\
\text { hospital for more } \\
\text { than one week } \\
\text { / Mean age } 27 \\
\text { weeks }\end{array}$ & $\begin{array}{l}62 \\
\text { hospitalized } \\
\text { in hospital }\end{array}$ & No & Yes $(76 \%)$ & $\begin{array}{l}\text { High fluency } \\
\text { of language, } \\
\text { no previous } \\
\text { history of } \\
\text { prisoning and } \\
\text { of cognitive } \\
\text { disorder }\end{array}$ & $\begin{array}{l}\text { Generalized Anxiety } \\
\text { Disorder-7, } \\
\text { Short Form Health } \\
\text { Survey-12, } \\
\text { Edinburgh Postnatal } \\
\text { Depression Scale (EPDS). }\end{array}$ & $\begin{array}{l}\text { - } 27 \% \text { had EPDS } \geq 10 \text { and } 13 \% \text { had GAD-7 } \geq 10 \text {. } \\
\text { - EPDS and GAD scores decreased across time. } \\
\text { - No participants scored positive on the EPDS } \\
\text { suicide screening question (question \#10). } \\
\text { - History of mental health diagnosis predicted } \\
\text { depression and anxiety symptoms at initial } \\
\text { survey. } \\
\text { - More than half of the women with an EPDS } \\
\geq 10 \text { reported that they did not have a history } \\
\text { of a mental health diagnosis. } \\
\text { - } 77 \% \text { of women reported that they } \\
\text { would or maybe would benefit from a } \\
\text { supportive psychotherapy group during their } \\
\text { hospitalization }\end{array}$ \\
\hline $\begin{array}{l}\text { Thiagayson } \\
\text { et al., } 2013\end{array}$ & Singapore & $\begin{array}{l}\text { Cross } \\
\text { sectional/>23 } \\
\text { weeks }\end{array}$ & $\begin{array}{l}200 \\
\text { hospitalized } \\
\text { in hospital }\end{array}$ & No & Yes (83\%) & $\begin{array}{l}\text { High } \\
\text { proficiency in } \\
\text { language }\end{array}$ & $\begin{array}{l}\text { State-Trait Anxiety Inventory, } \\
\text { Edinburgh Postnatal } \\
\text { Depression Scale, } \\
\text { Mini International } \\
\text { Neuropsychiatric Interview } \\
\text { (Structured Interview for } \\
\text { Axis I Disorders). }\end{array}$ & $\begin{array}{l}\text { - } 11 \% \text { major (EPDS } 8 / 9 \text { ) depression and } 7 \% \text { had } \\
\text { minor depression. } \\
\text { - }-12.5 \% \text { had anxiety disorders, and } 5 \% \text { had } \\
\text { depression with comorbid anxiety. }\end{array}$ \\
\hline
\end{tabular}


Denis et al., France Cross sectional/ 55 2012 8-36 weeks hospitalized
in health centre or bed-rest in home

No Yes $(90 \%)$ No

129

Brandon et
al., 2008

USA

Cross sectional/

7-38 weeks

hospitalized

in hospital
No

\section{refer}

Does not psychotherapy,
high fluency
in language, history of at least one hospitalization in present pregnancy
No previous

history

of mental

disorder, high

fluency of

language
Edinburgh Postnatal Depression Scale (EPDS) High Risk Pregnancy Stress Scale (HRPSS),

Revised Prenatal Coping Inventory,

Rosenberg Self-Esteem Scale.

Edinburgh Postnatal Depression Scale (EPDS) Mini International

Neuropsychiatric Interview (Structured Interview for Axis I Disorders), Dyadic Adjustment Scale, Maternal Antenatal Attachment Scale.

\section{Edinburgh Postnatal}

No previous history of psychotic pathology, high fluency in

language
Depression Scale (EPDS)

Mini International

Neuropsychiatric Interview

(Structured Interview for

Axis I Disorders),

Hospital Anxiety and

Depression Scale
- Mean score for EPDS was 14.23.

- 58\% had EPDS > 14

- Mean score of HRPSS was 42.4.

- No significant differences on EPDS and HRPSS scores between women hospitalized in birth centre of bed-resting in home.

- Predictive factors of depression included low self-esteem, low informational support coping and high avoidance coping

- Mean score for EPDS was 9.5.

- 44. $2 \%$ had EPDS $>11$

- 19\% met the DSM-IV criteria for depression

- Relationship satisfaction, antenatal attachment, lower annual income and absence of insurance were significantly associated with higher score of EPDS. Previous history of psychiatric diagnosis was not significantly related to depression.

- Mean score for EPDS was 9.3 and for HAD was 13.4 .

- 25\% had major depression based on MINI and EPDS > 11.5 
cervical changes, gestational diabetes, placenta abruption, placenta previa, hyperemesis. No study did not measure distress levels of husbands.

\section{Psychological instruments}

Psychological outcomes were conceptualized in terms of self-reported symptoms of anxiety and/ or depression and were assessed by general and pregnancy-specific validated questionnaires. Most of the studies used a pregnancy-related depression instrument. Most specifically, studies by Gourounti et al. [10], Byatt et al. [13], by Thiagayson et al. [18], by Denis et al. [16], by Brandon et al. [14] and by Adouard et al. [17] used the Edinburg Postnatal Depression Scale (EPDS) for measuring depressive symptomatology during pregnancy. Various general depression instruments were used and included the Center for Epidemiological Studies-Depression [15], the Profile of Mood States- Depression [15], the Mini International Neuropsychiatric Interview [14, 17, 18]. Various general anxiety instruments were used and included the State-Trait Anxiety Inventory [10, 18], the Generalized Anxiety Disorder-7 [13], the Short Form Health Survey-12 [13] and the Hospital Anxiety Depression Scale [17]. One study used a questionnaire measuring the anxiety specifically related to the pregnancy (High Risk Pregnancy Scale) [16].

\section{Prevalence of antenatal anxiety and depression in high-risk pregnancy}

According to the findings of the present review the prevalence of antenatal depression in high risk pregnant women range from $18 \%$ to $58 \%$ and the prevalence of antenatal anxiety is almost 13\%. More specifically, in the study by Gourounti et al. 10, which was conducted in Greece, the high-risk pregnant women high mean scores of state and trait anxiety and more than half of women (53.4\%) had depressive symptomatology, assessed by the EPDS (>11). In study by Gourounti et al. [10] it was noteworthy that almost $10 \%$ of the participants scored positively on the EPDS suicide screening question. However, in the studies by Byatt et al. [13], by Thiagayson et al. [18] and by Adouard et al. [17], the prevalence of antenatal depression, assessed by the EPDS, was lower $(27 \%, 18 \%$ and $25 \%$ respectively) and the rate of antenatal anxiety was almost $13 \%$. In studies by Denis et al. [16] and by Brandon et al. [14] the prevalence of antenatal depression was higher ( $58 \%$ and $44.2 \%$ respectively). It is noteworthy that the prevalence of antenatal depression in study by Denis et al. [16], in which the participants were bed rested in home or were hospitalized in a health centre, were extremely high (58\%) as more than half of women had major depression. It is also extremely interesting that in study by Denis et al. [16] the rates of antenatal depression and antenatal anxiety (assessed by a pregnancy-specific questionnaire) was not statistically different between the women who bed rested in home and women who hospitalized in a health centre.

\section{Rates of antenatal anxiety and depression across hospitalization}

Two studies assessed the levels of antenatal anxiety and depression across time during hospitalization. More specifically, the study by Byatt et al. [13] assessed the prevalence of anxiety and depression in hospital admission and on a weekly basis for the women who remained in the hospital for more than one week. They found a statistically significant decrease in EPDS and GAD-7 scores throughout the course of the hospitalization. In study by study by Maloni et al. [15] the rate of antenatal depression was assessed in admission and on second and fourth week during hospitalization. The rate was significantly declined from admission to 4 weeks of hospitalization.

\section{Psychosocial and demographic predictors of antenatal depression and anxiety in high-risk pregnancy}

Only three studies explored the psychosocial and demographic factors that related to antenatal anxie- 
ty and depression levels of hospitalized high-risk pregnant women. In the study by Byatt et al. [13], women who reported a history of mental health treatment or a history of mental health disorder were more likely to have depression in pregnancy. It is interesting that $77 \%$ of women participating in study by Byatt et al. 13 reported that they would benefit from a supportive psychotherapy group during hospitalization. The study by Denis et al. [16] demonstrated a significant association between higher depressive symptoms with higher use of avoidance coping strategies, lower self-esteem and lower satisfaction with informational support. They also revealed a significant association between higher levels of anxiety with younger age. The study by Brandon et al. [14] concluded that higher levels of depressive symptoms significantly related with lower relationship satisfaction, lower annual income, lower antenatal attachment and absence of insurance. The study by Brandon et al. [14] did not find a significant association between previous history of psychiatric diagnosis and antenatal depression.

\section{Discussion}

The aim of this review was to determine the findings from quantitative studies that assessed the prevalence of antenatal anxiety and depression in highrisk pregnant women hospitalized or bed-rested in home. The search results of this review revealed that a substantial body of literature has been published in the last 10 years.

Psychological stress was usually assessed in terms of general anxiety, pregnancy-specific anxiety and depression. General anxiety was measured most frequently by the State-Trait Anxiety Inventory and depressive symptoms by the Edinburgh Postnatal Depression Scale.

The review findings regarding the general anxiety level in high-risk pregnancy indicated that the rates of general anxiety are approximately 13\%. Howe- ver, very few studies have explored the rates of general anxiety in this population and therefore the evidence is still inconclusive. It is noteworthy that only one study used a pregnancy-specific anxiety instrument 16 . The review findings regarding the antenatal depression level in high-risk pregnancy indicated that the rate ranges from $18 \%$ to $58 \%$. Based on previous relevant literature, the rate of antenatal depression ranges from $4.8 \%$ up to 40 $\%$. [2, 3, 4] Therefore, it may be concluded that rates of depression symptoms in high-risk pregnant women were higher than those of pregnant women with a low risk pregnancy. It is notable that the depressive symptomatology was assessed by the majority of studies with the Edinburgh Postnatal Depression Scale which can be considered a pregnancy-specific and not a general instrument. Therefore, the evidence regarding the depressive level of high-risk pregnancy seems consistent and emerges from studies that have used a valid instrument that has the sensitivity to detect depressive symptoms during pregnancy.

The review findings also indicated that anxiety and depression symptoms decreased throughout the course of hospitalization. This finding may be due to the fact that as a high-risk pregnancy progresses and the probability of fetal complications decrease there is a relief of stress and an increase of positive effect and optimism regarding the pregnancy outcome.

The review findings also indicated the main psychosocial variables that related to antenatal anxiety and depression levels of high-risk pregnant women were a history of mental health treatment or a history of mental health disorder, high use of avoidance coping strategies, low satisfaction with informational support, low self-esteem and low relationship satisfaction. In addition the review findings showed that the main demographic variables that related to antenatal stress were young age, low annual income and absence of insurance. The theoretical model of stress, appraisal and coping by Lazarus and Folk- 
man [19] may explain the review findings. According to this model, individual personality characteristics (e.g. self-esteem), maladaptive coping skills, and low social support are considered risk factors of emotional stress.

It is noteworthy that the review findings suggested that the levels of anxiety and depression symptoms were the same between women hospitalized in a health centre and women bed-rested in home. Therefore, it seems that all high-risk pregnant women independently of the place of hospitalization or bed-resting may need psychosocial support.

Overall, the review findings regarding some aspects of high-risk pregnancy were consistent. However, the evidence regarding some other dimensions was inconclusive. Some of the inconsistencies in the review findings may have been due to methodological differences of the included studies. For example, the included studies varied regarding the general measures of anxiety and sample sizes.

The findings of this review should be interpreted after considering some methodological limitations. First, this review included only quantitative studies and studies in English. Studies that used a qualitative or mixed methodology design were excluded and, thus, a deeper understanding of the high-risk pregnancy might be constricted to some extent. In addition, studies that were written in other than English language were excluded, and this may have restricted the findings of the review. However, the dissemination bias was diminished by reviewing the reference list of retrieved papers and searching the reference list of previous review papers.

Furthermore, several studies assessed psychosocial stress, and more specifically antenatal anxiety, in high-risk pregnancy by different instruments, and for these reason it was difficult to compare their results. Another limitation of all the included studies was that they did not used a control group of low-risk pregnant women in order to compare the levels of anxiety and depression symptoms between the high-risk pregnant and the low-risk pregnant women. In addition, the vast majority of studies did not use a pregnancy-specific instrument for measuring antenatal anxiety. Because these measures have been primarily developed for use in general populations, they can contain items that may be interpreted differently by a specific medical population [1], such as is in high-risk pregnant women. Such items may lack the sensitivity to detect important concerns specific to high-risk pregnancy.

\section{Conclusion and implications for research and practice}

Overall, it seemed that the women with a high-risk pregnancy have high levels of pregnancy-specific depression. However, the evidence regarding the general anxiety level in high-risk pregnancy was inconclusive. Therefore, to overcome these inconsistencies, future studies should assess anxiety levels in high-risk pregnancy by using pregnancy-specific instruments. These pregnancy-specific measures may detect and assess the multidimensionality of high-risk pregnancy stress. In addition, future studies should use the same standard instruments and timing of stress assessment for facilitating comparability across studies. Future studies should also use matched control groups of low-risk pregnant women in order to facilitate comparability between low-risk and high-risk pregnancy.

This review provides insight into psychological reactions and adjustment in high-risk pregnancy. It is hoped that information obtained from this review will help health care professionals to early identify high-risk pregnant women who might experience anxiety and depression symptoms and need support. Therefore, health care professionals should enhance the implementation of psychological screening to populations of high-risk pregnant women hospitalized in a hospital or a health centre or even bed-rested in home. They should also provide counselling services for stressed pregnant women. 


\section{References}

1. Gourounti K, Lykeridou K, Taskou C, Kafetsios K, Sandall J. (2012) A survey of worries of pregnant women: Reliability and validity of the Greek version of the Cambridge Worry Scale. Midwifery, 28(6): 746-753.

2. Mohammad K, Gamble J, Creedy D. (2011) Prevalence and factors associated with the development of antenatal and postnatal depression among Jordanian women. Midwifery 27: 238-245

3. Faisal-Cury A, Savoia M, Menezes P. (2012) Coping style and depressive symptomatology during pregnancy in a private setting sample. Span J Psychol 15(1): 295-305.

4. Gourounti K., Anagnostopoulos F., Lykeridou K., Griva F., Vaslamatzis G. (2013) Prevalence of women's worries, anxiety and depression during pregnancy in a public hospital setting in Greece. Journal of Clinical and Expimental Obstetrics Gynecology, 40(4): 581-583.

5. Faisal Cury A, Menezes R. 2007. Prevalence of anxiety and depression during pregnancy in a private setting sample. Archives of Women's Mental Health 10, 25-32.

6. Lee A, Chong C, Chiu H, Lam S, Fong D. (2007) Prevalence, course, and risk factors for antenatal anxiety and depression. Obstet Gynecol 110: 1102-1112.

7. Leigh B, Milgrom J. (2008) Risk factors for antenatal depression, postnatal depression and parenting stress. BMC Psychiatry, 8: 24.

8. Bodecs T, Horvath B, Kovacs L, Diffelne Nemeth M, Sandor J. (2009) Prevalence of depression and anxiety on a population based Hungarian sample. Orv Hetil, 150(41): 1888-1893.

9. Qiao YX, Wang J, Ablat A. The prevalence and related risk factors of anxiety and depression symptoms among Chinese pregnant women in Shanghai. Austr New Zeal J Obstet Gynaecol 2009; 49: 185-190.

10. Gourounti K., Karapanou V., Karpathiotaki N., Vaslamatzis G. (2015) Anxiety and depression of high risk pregnant women hospitalized in two public hospital settings in Greece. International Archives of Medicine. 8(25): 1-6.

11. Penticuff $\mathrm{JH}$. Psychologic implications in high-risk pregnancy. Nursing Clinics of North America 1982; 7(1): 69-78.

12. Erik von Elm E, D. Altman, M. Egger, S. Pocock, P. Gøtzsche, and J. Vandenbroucke. 2007. The Strengthening the Reporting of Observational Studies in Epidemiology (STROBE) Statement: Guidelines for Reporting Observational Studies. Annals of Inter Med 147: 573-7.

13. Byatt N., Hicks-Courant K., Davidson A., Levesque R., Mick E., Allison J., et al. (2014) Depression and anxiety among high-risk pregnancy obstetric inpatients. General Hospital Psychiatry, 36: 644-649.

14. Brandon, A.R., Trivedi, M.H., Hynan, L.S., Miltenberge, P.D., Labat, D.B., Rifkin, J., Stringer A. (2008), Prenatal Depression in Women Hospitalized for Obstetric Risk. National Institute of Health, 69(4), 635-643.
15. Maloni, J.A., Park, S., Anthony, M.K., Musil, C.M. (2005), Measurement of Antepartum Depressive Symptoms during High-Risk Pregnancy. Research in Nursing \& Health, 28, 16-26.

16. Denis, A., Michaux, P. \& Callohan S. (2012), Factors implicated in moderating the risk for depression and anxiety in high risk pregnancy. Journal of Reproductive and Infant Psychology, 30 (2), 124-134.

17. Adouard, F., Glangeaud- Freudenthal, N.M.C. \& Golse, B. (2005), Validation of the EPDS in a sample of women with highrisk pregnancies in France. Archives of Women's Mental Health, $8(2), 89-95$.

18. Thiagayson, P., Krishnaswamy, G., Lim, M.L., Sung, S.C., Haley, C.L., Fung, D.S.S., Allen, J.C. \& Chen, H. (2013), Depression and anxiety in Singaporean high-risk pregnancies - prevalence and screening. General Hospital Psychiatry, 35 (2), 112-116.

19. Lazarus R, Folkman S. Stress, appraisal and coping. New York: Springer 1984

\section{Comment on this article:}

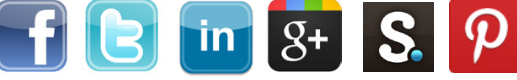

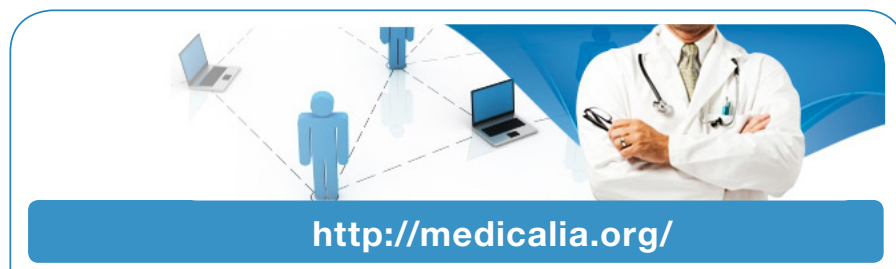

Where Doctors exchange clinical experiences, review their cases and share clinical knowledge. You can also access lots of medical publications for free. Join Now!

\section{Publish with iMedPub}

\section{http://www.imed.pub}

International Archives of Medicine is an open access journal publishing articles encompassing all aspects of medical science and clinical practice. IAM is considered a megajournal with independent sections on all areas of medicine. IAM is a really international journal with authors and board members from all around the world. The journal is widely indexed and classified Q1 in category Medicine. 